\title{
Lipid biomarkers in aeolian sediments under desert pavements - potential and first results from the Black Rock Desert, Utah, USA, and Fuerteventura, Canary Islands, Spain
}

\author{
Marcel Lerch ${ }^{1}$, Marcel Bliedtner ${ }^{2}$, Christopher-Bastian Roettig ${ }^{1}$, Jan-Uwe Schmidt ${ }^{1}$, Sönke Szidat ${ }^{3}$, Gary Salazar $^{3}$, \\ Roland Zech $^{2,4}$, Bruno Glaser ${ }^{5}$, Arno Kleber ${ }^{1}$, and Michael Zech ${ }^{1,5}$ \\ ${ }^{1}$ Department of Geosciences, Institute of Geography, University of Technology Dresden, \\ Helmholtzstraße 10, 01069 Dresden, Germany \\ ${ }^{2}$ Institute of Geography and Oeschger Centre for Climate Change Research, Biogeochemistry and \\ Palaeoclimatology Group, University of Bern, Hallerstrasse 12, 3012 Bern, Switzerland \\ ${ }^{3}$ Department for Chemistry and Biochemistry and Oeschger Centre for Climate Change Research, \\ University of Bern, Freiestrasse 3, 3012 Bern, Switzerland \\ ${ }^{4}$ Institute of Geography, Chair of Physical Geography, Friedrich Schiller University Jena, \\ Löbdergraben 32, 07743 Jena, Germany \\ ${ }^{5}$ Institute of Agronomy and Nutritional Sciences, Soil Biogeochemistry, Martin Luther University \\ Halle-Wittenberg, Von-Seckendorff-Platz 3, 06120 Halle (Saale), Germany
}

Correspondence: $\quad$ Marcel Lerch (marcel.lerch@mailbox.tu-dresden.de)

Relevant dates: $\quad$ Published: 3 January 2018

How to cite: $\quad$ Lerch, M., Bliedtner, M., Roettig, C.-B., Schmidt, J.-U., Szidat, S., Salazar, G., Zech, R., Glaser, B., Kleber, A., and Zech, M.: Lipid biomarkers in aeolian sediments under desert pavements - potential and first results from the Black Rock Desert, Utah, USA, and Fuerteventura, Canary Islands, Spain, E\&G Quaternary Sci. J., 66, 103-108, https://doi.org/10.5194/egqsj-66-103-2018, 2018.

\section{Introduction}

The analysis of lipid biomarkers, particularly $n$-alkanes, has become a popular and widely applied tool in paleoenvironmental and climate research during the last decades (Zech et al., 2011). Whereas long-chain $n$-alkane homologues $\left(>n \mathrm{C}_{27}\right)$ with a strong odd-over-even predominance (OEP) are characteristic for higher plant leaf waxes, short-chain and mid-chain homologues $\left(n \mathrm{C}_{16}-n \mathrm{C}_{26}\right)$ indicate aquatic or microbial sources of $n$-alkanes. Furthermore, $n \mathrm{C}_{31}$ and $n \mathrm{C}_{33}$ were found to dominate in most grasses and herbs, whereas $n \mathrm{C}_{27}$ and $n \mathrm{C}_{29}$ were reported to dominate in most trees and shrubs (Zech et al., 2009). Therefore, sedimentary longchain $n$-alkanes have been used for reconstructing vegetation changes, among others, from loess-paleosol sequences (Zech et al., 2012, 2013).
In contrast, aeolian sediments under desert pavements, potentially very useful terrestrial archives in arid regions (Dietze et al., 2016; Schmidt, 2008; Faust et al., 2015), have not been investigated for lipid biomarkers so far. Here, apart from long-chain $n$-alkanes as proxies for vegetation reconstructions, short- and mid-chain $n$-alkanes may also help to shed light on the role of soil microorganisms and biological soil crusts for the formation of desert soils.

Therefore, the aim of this study was to test the applicability of $n$-alkane analyses in such settings. We chose two pilot study areas, namely the Black Rock Desert, which is located in western Utah (USA), and the island of Fuerteventura, which belongs to the Canary Islands (Spain). Specifically, we addressed the following objectives and research questions: 
1. Quantification of $n$-alkane biomarkers in the investigated aeolian sediments under desert pavements.

2. Do the leaf-wax-derived long-chain $n$-alkanes of aeolian sediments under desert pavements allow us to distinguish between different vegetation types?

3. Are the $n$-alkane concentrations in aeolian sediments under desert pavements high enough to carry out radiocarbon dating?

4. Do short- and mid-chain $n$-alkanes as well as the ${ }^{14} \mathrm{C}$ ages of the $n$-alkanes provide information about the genesis of desert soils under desert pavements?

\section{Material and methods}

\subsection{Study areas}

One study area is located in the Black Rock Desert (Utah, USA). This semiarid region belongs to the southern part of the Sevier Desert and covers an area of $7000 \mathrm{~km}^{2}$. The geographic coordinates are northernmost point $39^{\circ} 16^{\prime} \mathrm{N}$, southernmost point $38^{\circ} 37^{\prime} \mathrm{N}$, easternmost point $112^{\circ} 15^{\prime} \mathrm{W}$ and westernmost point $113^{\circ} 02^{\prime} \mathrm{W}$. To the west and the east, the Black Rock Desert is bounded by mountain ranges. Following the effective climate classification by Köppen, the climate for this study area corresponds to a cold arid steppe climate (BSk) (Schmidt, 2008). The natural vegetation mainly consists of Artemisia tridentata and a high variation of different shrubs. It was influenced by anthropogenic effects (Schmidt, 2008).

The second study area is located in the northern part of the Canary Island Fuerteventura. Two soil profiles were chosen for sampling. The coordinates of soil profile 1 (SP1) are $28^{\circ} 65^{\prime} 60^{\prime \prime} \mathrm{N}$ and $13^{\circ} 87^{\prime} 07^{\prime \prime} \mathrm{W}$. Soil profile 2 (SP2) is classified with the coordinates $28^{\circ} 65^{\prime} 15^{\prime \prime} \mathrm{N}$ and $13^{\circ} 85^{\prime} 14^{\prime \prime} \mathrm{W}$. Volcanic landforms and Quaternary sand dunes are typical for the study area on Fuerteventura (Criado et al., 2004). The northern part of the island has an arid to semiarid climate. According to the climate classification by Köppen, there is a hot arid desert climate (BWh). Because of the arid climate conditions, no abundant vegetation exists, comprising few shrubs, disperse grassland and various kinds of lichens.

\subsection{Sampling}

For this biomarker pilot study we chose 26 samples in total (Table 1). The 22 samples from the Black Rock Desert are from 6 soil profiles and were previously investigated for certain parameters, such as grain size distribution, total organic carbon (TOC) and carbonate content $\left(\mathrm{CaCO}_{3}\right)$ (Schmidt, 2008). The soil profiles are Ice Springs 1 (IS1), Lava Ridge 3 (LR3), Pavant Butte 4 (PB4), Pot Mountain 1 (PM1), Pot Mountain 2 (PM2) and Tabernacle Hill 1 (TH1).
Samples were taken for each horizon and therefore from various depths. According to the grain size distribution, the aeolian sediments of the soil profiles IS1, LR3, PM1 and TH1 can be qualified as desert loess because of their high amount of fine sand and coarse silt. The profiles PB4 and PM2 have lower silt contents, but they can also be qualified as aeolian sediments. The TOC values range from 0.3 to $1.6 \%$.

The four samples from Fuerteventura originate from two soil profiles (samples $\mathrm{F} / 335$ and F/336 from soil profile SP1 and samples F/337 and F/338 from soil profile SP2), which are located in the northern part of the island and are approximately $1.5 \mathrm{~km}$ apart. Although TOC analyses have not been carried out for these samples, a comparison with the study of Faust et al. (2015) suggests TOC values smaller than $0.25 \%$. Both soil profiles SP1 and SP2 have desert pavements on the soil surface. Desert pavements mainly consist of basaltic rocks for both study areas.

\section{$2.3 n$-Alkane biomarker quantification and radiocarbon dating}

Total lipid extracts (TLEs) were obtained using Soxhlet apparatuses and DCM : MeOH $(2: 1)$ as solvent for $24 \mathrm{~h}$. After drying the TLEs under nitrogen, a lipid fractionation was realized via aminopropyl columns. The aliphatic fraction, containing the $n$-alkanes, was eluted with $3 \mathrm{~mL} n$-hexane. Quantification of the $n$-alkanes was performed on a gas chromatograph coupled to a flame ionization detector (GC-FID) and an external alkane standard mixture $\left(n \mathrm{C}_{8}-n \mathrm{C}_{40}\right)$.

Given that the $n$-alkane chromatograms from the Black Rock Desert and Fuerteventura yielded large UCM humps (unresolved complex mixture) as they are often observed also for loess-paleosol samples (Zech et al., 2013), a second purification step was necessary before radiocarbon dating could be performed according to the procedure described by Zech et al. (2017). In brief, the $n$-alkanes were purified over silver nitrate $\left(\mathrm{AgNO}_{3}\right.$-coated silica gel) and zeolite (Zeolite $\left.\mathrm{A}\right)$ columns. The zeolite, containing the purified $n$-alkanes, was dissolved using hydrofluoric acid. After liquid-liquid extraction with $n$-hexane, the purified $n$-alkanes were measured and quantified again on the GC-FID.

Based on the $n$-alkane amounts per sample, the location and the stratigraphical position, 10 samples were selected for radiocarbon dating $\left({ }^{14} \mathrm{C}\right)$ : IS1_1, IS1_3, PM1_3, TH1_1, TH1_3, LR3_1, LR3_4, F/335/3, F/336/3 and F/338/3 (Table 1 and Fig. 2). The amounts of $n$-alkanes ranged between 15 and $80 \mu \mathrm{g}$ per vial for the samples from Fuerteventura. For the samples from the Black Rock Desert, the $n$-alkane amounts ranged between 30 and $53 \mu \mathrm{g}$ per vial. Radiocarbon dating was carried out using accelerated mass spectrometry (AMS) at the University of Bern (Szidat et al., 2014). Results of radiocarbon dating were corrected for constant and cross contamination (Haas et al., 2017). All ${ }^{14} \mathrm{C}$ ages were calibrated using the Intcal 13 calibration curve (Table 1). 
Table 1. Soil profiles, sample list and $n$-alkane biomarker results from the Black Rock Desert, Utah, USA, and Fuerteventura, Canary Islands, Spain. TOC content is the total organic carbon content, TAC is the total $n$-alkane concentration, OEP is the odd-over-even predominance, LSR is the ratio of long-chain to short- and mid-chain $n$-alkanes, $n \mathrm{C}_{\max }$ is the dominant $n$-alkane homologue and $n$.a. indicates no value available.

\begin{tabular}{|c|c|c|c|c|c|c|c|c|c|c|c|c|}
\hline \multirow{2}{*}{$\begin{array}{l}\text { Sample } \\
\text { number } \\
\text { No. }\end{array}$} & \multicolumn{2}{|c|}{ Sample name } & \multirow{2}{*}{$\begin{array}{l}\text { Sample } \\
\text { label } \\
\text { Name }\end{array}$} & \multirow{2}{*}{$\begin{array}{r}\text { Average } \\
\text { value (depth) } \\
\mathrm{cm}\end{array}$} & \multirow{2}{*}{$\begin{array}{r}\text { TOC } \\
\text { content } \\
\%\end{array}$} & \multirow{2}{*}{$\begin{array}{r}\text { TAC } \\
\mu g^{-1}\end{array}$} & \multirow[t]{2}{*}{ OEP } & \multirow{2}{*}{$\begin{array}{r}\mathrm{LSR}^{\mathrm{b}} \\
\% \\
\%\end{array}$} & \multirow[t]{2}{*}{$n \mathrm{C}_{\max }$} & \multicolumn{2}{|c|}{${ }^{14} \mathrm{C}$ ages } & \multirow{2}{*}{$\begin{array}{l}\text { Desert } \\
\text { pavements }\end{array}$} \\
\hline & Soil profile & No. & & & & & & & & uncal years BP & cal years BP & \\
\hline 1 & IS 1 & 1 & IS1_1 & 2.5 & 1.6 & 1.11 & 6.84 & 86 & $n \mathrm{C}_{29}$ & $778 \pm 89$ & $733 \pm 84$ & initial \\
\hline 2 & IS 1 & 2 & IS1_2 & 7.5 & 0.9 & 0.51 & 9.25 & 83 & $n \mathrm{C}_{29}$ & & & \\
\hline 3 & IS1 & 3 & IS1_3 & 15.0 & 0.8 & 1.35 & 6.74 & 81 & $n \mathrm{C}_{29}$ & $3181 \pm 113$ & $3395 \pm 141$ & \\
\hline 4 & IS 1 & 4 & IS1_4 & 25.0 & n. a. & 0.17 & n.a. ${ }^{\mathrm{c}}$ & 34 & $n \mathrm{C}_{29}$ & & & \\
\hline 5 & LR3 & 1 & LR3_1 & 1.5 & 1.0 & 1.21 & 9.29 & 84 & $n \mathrm{C}_{29}$ & $1285 \pm 67$ & $1200 \pm 71$ & initial \\
\hline 6 & LR3 & 2 & LR3_2 & 6.5 & 0.7 & 0.57 & 8.98 & 87 & $n \mathrm{C}_{29}$ & & & \\
\hline 7 & LR3 & 3 & LR3_3 & 15.0 & n. a. & 0.35 & 6.70 & 76 & $n \mathrm{C}_{29}$ & & & \\
\hline 8 & LR3 & 4 & LR3_4 & 25.0 & n. a. & 0.83 & 3.48 & 70 & $n \mathrm{C}_{29}$ & $4340 \pm 77$ & $4960 \pm 128$ & \\
\hline 9 & LR3 & 5 & LR3_5 & 45.0 & n. a. & 0.34 & 2.79 & 64 & $n \mathrm{C}_{27}$ & & & \\
\hline 10 & PB4 & 1 & PB4_1 & 5.0 & 0.3 & 0.14 & 6.48 & 86 & $n \mathrm{C}_{29}$ & & & yes \\
\hline 11 & PB4 & 2 & PB4_2 & 13.0 & 0.4 & 0.10 & n.a. ${ }^{\mathrm{c}}$ & 83 & $n \mathrm{C}_{29}$ & & & \\
\hline 12 & PB4 & 3 & PB4_3 & 20.0 & n. a. & 0.13 & 8.66 & 62 & $n \mathrm{C}_{29}$ & & & \\
\hline 13 & PB4 & 4 & PB4_4 & 29.5 & n. a. & 0.00 & n.a. ${ }^{c}$ & n.a. & n.a. & & & \\
\hline 14 & PB4 & 5 & PB4_5 & 47.5 & n.a. & 0.00 & n.a. ${ }^{\mathrm{c}}$ & n.a. & n.a. & & & \\
\hline 15 & PM1 & 1 & PM1_1 & 2.5 & 0.5 & 0.42 & 10.15 & 75 & $n \mathrm{C}_{29}$ & & & yes \\
\hline 16 & PM1 & 2 & PM1_2 & 8.5 & 0.5 & 0.59 & 10.78 & 76 & $n \mathrm{C}_{29}$ & & & \\
\hline 17 & PM1 & 3 & PM1_3 & 17.0 & n. a. & 0.91 & 9.78 & 67 & $n \mathrm{C}_{29}$ & $7830 \pm 123$ & $8689 \pm 16$ & \\
\hline 18 & PM2 & 1 & PM2_1 & 4.0 & 0.4 & 0.28 & 13.94 & 76 & $n \mathrm{C}_{31}$ & & & yes \\
\hline 19 & PM2 & 2 & PM2_2 & 19.0 & 1.1 & 0.36 & 6.73 & 24 & $n \mathrm{C}_{29}$ & & & \\
\hline 20 & TH1 & 1 & TH1_1 & 2.5 & 1.0 & 0.88 & 7.07 & 83 & $n \mathrm{C}_{29}$ & $1587 \pm 90$ & $1490 \pm 96$ & initial \\
\hline 21 & TH1 & 2 & TH1_2 & 7.5 & 0.5 & 0.79 & 7.25 & 86 & $n \mathrm{C}_{29}$ & & & \\
\hline 22 & TH1 & 3 & TH1_3 & 15.0 & n. a. & 0.69 & 6.58 & 80 & $n \mathrm{C}_{29}$ & $3767 \pm 75$ & $4149 \pm 120$ & \\
\hline 23 & F/335/SP1 & 3 & $\mathrm{~F} / 335 / 3$ & 30.0 & $<0.25^{\mathrm{a}}$ & 0.62 & 11.23 & 90 & $n \mathrm{C}_{33}$ & $3732 \pm 75$ & $4095 \pm 116$ & yes \\
\hline 24 & F/336/SP1 & 3 & $\mathrm{~F} / 336 / 3$ & 60.0 & $<0.25^{\mathrm{a}}$ & 0.28 & 6.55 & 85 & $n \mathrm{C}_{31}, n \mathrm{C}_{33}$ & $5456 \pm 82$ & $6236 \pm 101$ & \\
\hline 25 & F/337/SP2 & 3 & $\mathrm{~F} / 337 / 3$ & 22.5 & $<0.25^{\mathrm{a}}$ & 0.15 & n.a. ${ }^{\mathrm{c}}$ & 71 & $n \mathrm{C}_{29}, n \mathrm{C}_{31}$ & & & yes \\
\hline 26 & F/338/SP2 & 3 & $\mathrm{~F} / 338 / 3$ & 40.0 & $<0.25^{\mathrm{a}}$ & 1.87 & 1.12 & 77 & $n \mathrm{C}_{29}, n \mathrm{C}_{31}$ & $19734 \pm 227$ & $23760 \pm 276$ & \\
\hline
\end{tabular}

${ }^{a}$ No own values for TOC available. TOC values refer to results of Faust et al. (2015). Study area: Lajares III, Fuerteventura, Spain.

b Modified after Zech et al. (2012) with long-chain $n$-alkanes $\geq n \mathrm{C}_{27}$ and short- and mid-chain $n$-alkanes $<n \mathrm{C}_{27}$.

c No even $n$-alkanes detectable.

\section{Results}

The total $n$-alkane concentrations (TAC $=$ sum of $n \mathrm{C}_{16}$ to $n \mathrm{C}_{33}$ ) for all 26 samples range from 0 to $1.87 \mu \mathrm{g} \mathrm{g}^{-1}$ sediment (Table 1). For comparison, $n$-alkane concentrations of

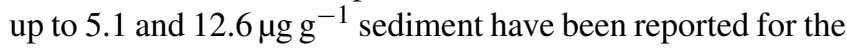
long-chain $n$-alkanes from loess-paleosol sequences alone (Zech et al., 2012, 2013). This reflects the very low sedimentary organic carbon contents of the aeolian sediments under desert pavements.

The long-chain $n$-alkanes clearly dominate over short- and mid-chain $n$-alkanes (ratio of long-chain to short- and midchain $n$-alkanes - LSR), as it is typically observed for plant leaf waxes. The percentages of long-chain to total $n$-alkanes are greater than or equal to $71 \%$ in the topsoils and generally become smaller with increasing soil depth (LSR, Table 1). This likely indicates that the soil organic matter is becoming stronger degraded in the subsoils compared to the topsoils. Whereas the $n$-alkane homologue $n \mathrm{C}_{29}$ is predominant in most samples from the Black Rock Desert, $n \mathrm{C}_{29}, n \mathrm{C}_{31}$ and/or $n \mathrm{C}_{33}$ predominate in the samples from Fuerteventura $\left(n \mathrm{C}_{\max }\right.$, Table 1).

The OEP, which is typically high in fresh plant material and decreases with degradation, ranges from 1 to 14 for all investigated samples (Table 1 and Fig. 1) and, similar to the LSRs, generally decreases with increasing soil depth.

It is generally considered that a carbon amount of $>20 \mu \mathrm{g} \mathrm{C}$ sample $^{-1}$ is needed for radiocarbon dating. This prerequisite was fulfilled for 14 of the total 26 prepared $n$ alkane samples and for 9 of the samples chosen for radiocarbon dating (except sample F/336/3 with $15 \mu \mathrm{g}$ C). The $n$-alkane ${ }^{14} \mathrm{C}$ ages range from $733 \pm 84$ to $23760 \pm 276 \mathrm{cal}$ years BP and are stratigraphically consistent for all soil profiles with two ${ }^{14} \mathrm{C}$ results (Table 1 and Fig. 2). This also holds true for sample $F / 336 / 3$, which furthermore does also not strike by its measurement uncertainty and is therefore considered to be robust. 

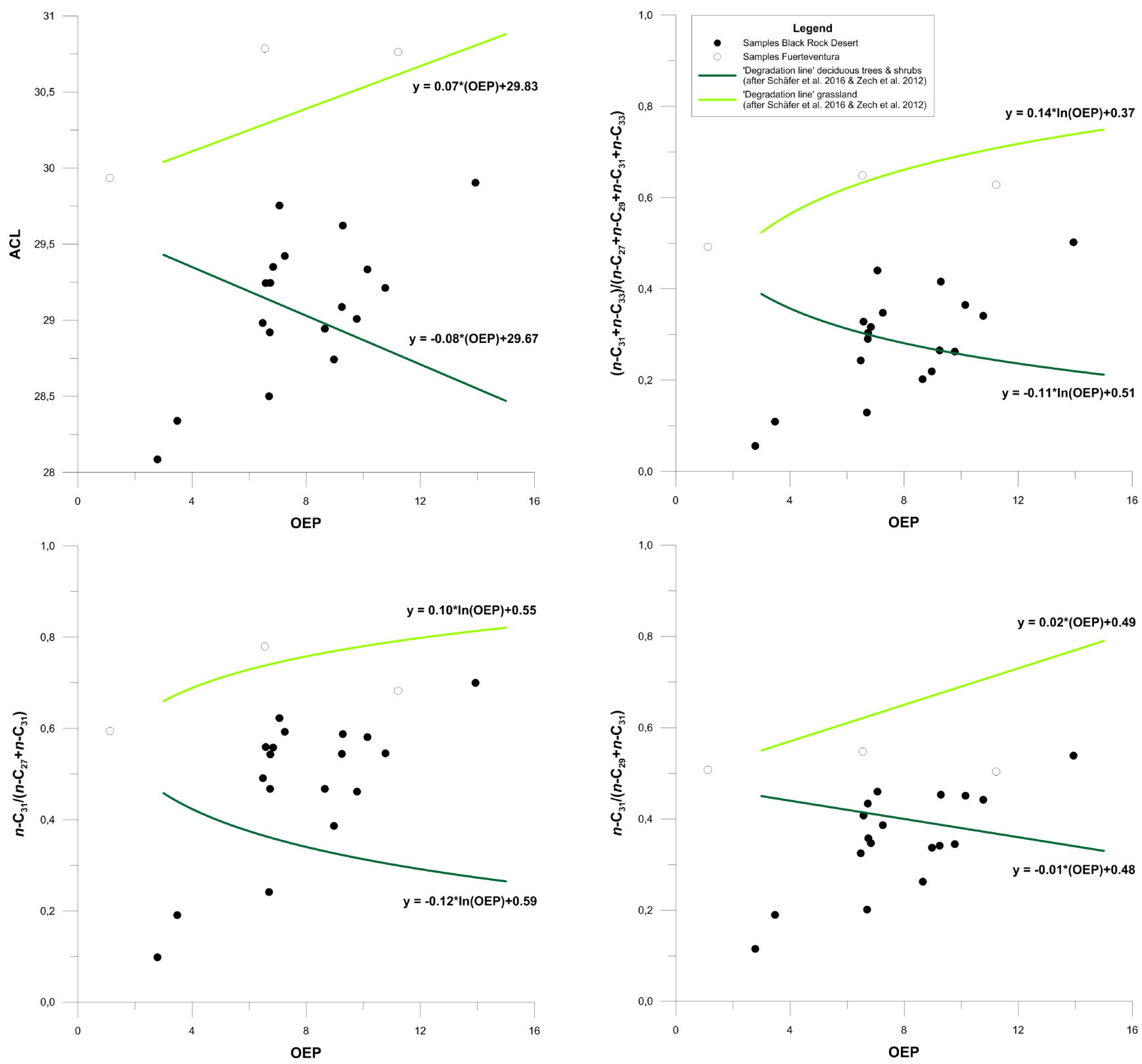

Figure 1. Endmember plots for samples of the study areas Black Rock Desert, Utah, USA, and Fuerteventura, Canary Islands, Spain. Degradation lines for grassland and deciduous trees and shrubs, respectively, are derived from datasets of Schäfer et al. (2016) and Zech et al. (2012). ACL is the average chain length and OEP is the odd-over-even predominance.

\section{Discussion}

\subsection{Vegetation reconstruction}

The predominant $n$-alkane homologue $\left(n \mathrm{C}_{\max }\right)$ of most samples from the Black Rock Desert is $n \mathrm{C}_{29}$, whereas $n \mathrm{C}_{29}, n \mathrm{C}_{31}$ and/or $n \mathrm{C}_{33}$ predominate in the samples from Fuerteventura $\left(n \mathrm{C}_{\max }\right.$, Table 1$)$. This may serve as a first indication that the $n$-alkanes in the Black Rock Desert are mainly shrub derived, whereas the $n$-alkanes on Fuerteventura are mainly grass derived. Indeed, this interpretation is in agree- ment with the modern vegetation, which is shrub dominated in the Black Rock Desert and grass dominated on Fuerteventura. The very low $n$-alkane concentrations in the subsoils of the soil profiles allow no reliable statements on the past vegetation cover for both study areas.

As mentioned above, organic matter degradation may affect the $n$-alkane patterns (LSR, OEP and $\left.n \mathrm{C}_{\max }\right)$. Therefore, we plotted various $n$-alkane ratios (ACL, $\quad\left(n \mathrm{C}_{31}+n \mathrm{C}_{33}\right) /\left(n \mathrm{C}_{27}+n \mathrm{C}_{29}+n \mathrm{C}_{31}+n \mathrm{C}_{33}\right)$, $n \mathrm{C}_{31} /\left(n \mathrm{C}_{27}+n \mathrm{C}_{31}\right)$ and $\left.n \mathrm{C}_{31} /\left(n \mathrm{C}_{29}+n \mathrm{C}_{31}\right)\right)$ against the 

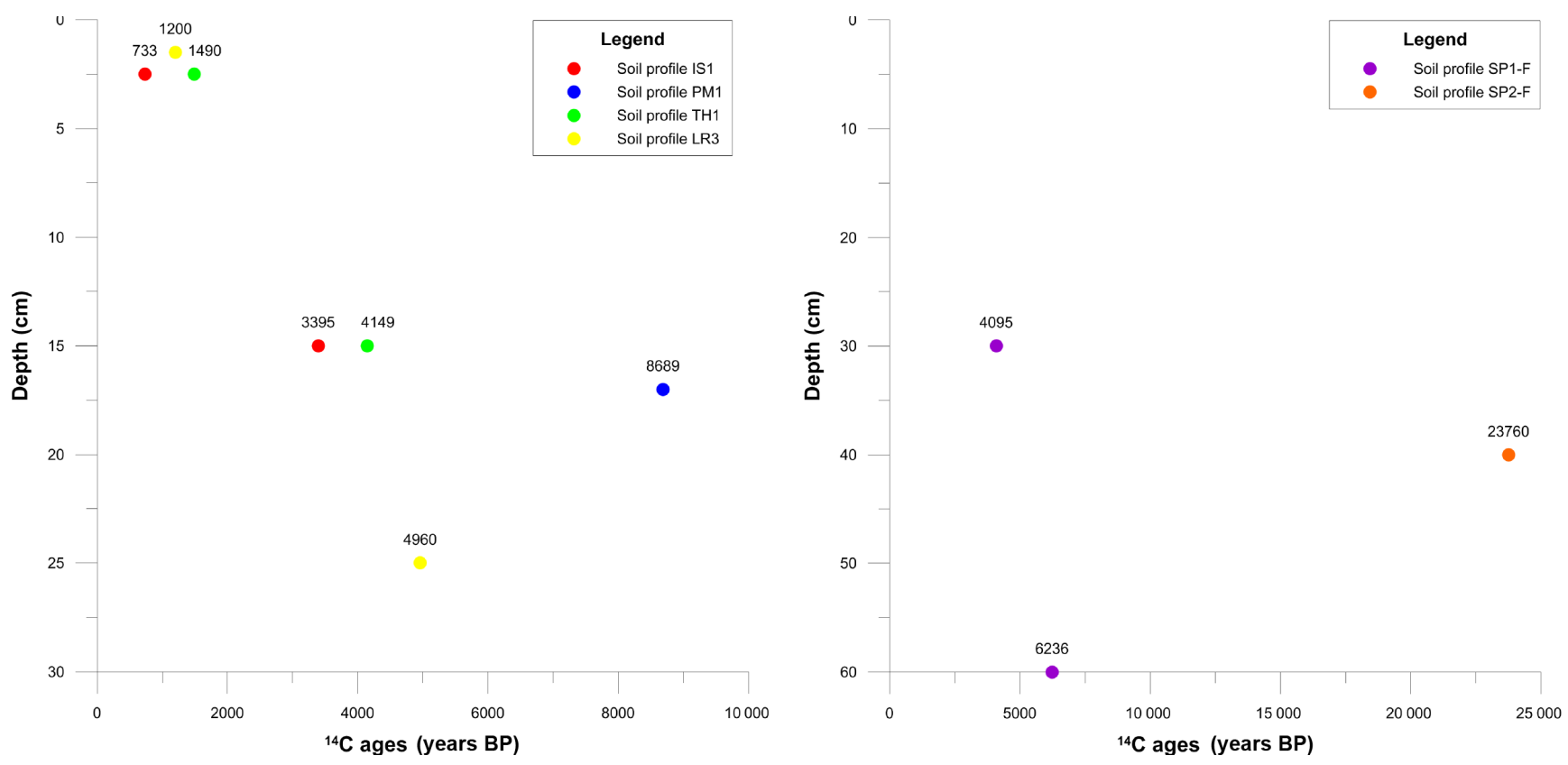

Figure 2. $n$-Alkane ${ }^{14} \mathrm{C}$ ages for soil profiles from the Black Rock Desert, Utah, USA (left), and Fuerteventura, Canary Islands, Spain (right). All ${ }^{14} \mathrm{C}$ ages are plotted as calibrated ages. IS1 is Ice Springs 1, PM1 is Pot Mountain 1, TH1 is Tabernacle Hill 1, LR3 is Lava Ridge 3, SP1-F is stone pavement sample location 1 - Fuerteventura and SP2-F is stone pavement sample location 2 - Fuerteventura.

degradation proxy OEP (Fig. 1). This approach was originally introduced by Zech et al. (2009), further developed by Zech et al. (2012, 2013) and Schäfer et al. (2016), and allows us to illustrate and account for degradation effects. The "degradation lines" for grassland vs. deciduous trees and shrubs are based on modern plant and soil reference dataset. Samples from Fuerteventura plot close to the degradation line of grassland, whereas the samples from the Black Rock Desert plot - albeit with a large scattering - around or closer to the degradation line of deciduous trees and shrubs (Fig. 1).

This illustrates the potential of $n$-alkane analyses in aeolian sediments under desert pavements for environmental and vegetation reconstruction. For this study, we refrain from calculating the percent of grass-herb versus shrub-tree contributions using endmember modeling given the lack of continuous archives. Nevertheless, we would like to point to the updated functions in Fig. 1 describing the degradation lines, which will make endmember-model calculations possible in future studies.

\subsection{Potential for studying desert soils and contribution of soil microorganisms}

The high LSR and OEP values in our samples indicate that the $n$-alkanes in aeolian sediments under desert pavements are primarily plant derived. Lower LSR and OEP values with increasing depth probably reflect enhanced degradation, but there is no evidence at least from the $n$-alkane biomarkers for the abundant occurrence of soil microorganisms forming biological soil crusts.
While the $n$-alkane ${ }^{14} \mathrm{C}$ ages are stratigraphically consistent, it is noteworthy that the $n$-alkanes within the topmost $2.5 \mathrm{~cm}$ yielded ages $>733 \mathrm{cal}$ years BP. $n$-Alkanes at or below $15 \mathrm{~cm}$ soil depth yielded ages $>3395$ cal years BP. This suggests first that the input of modern $n$-alkanes to the topsoils is very low - likely reflecting the low biomass production in the arid study areas - and that there is no substantial incorporation of modern $n$-alkanes by roots or rhizomicrobial processes to the subsoils (Zech et al., 2017). Moreover, this suggests that the accumulation and sedimentation rates are very low or erosive processes by heavy rainfall events or deflation - possibly induced by grazing - cannot be excluded.

\section{Conclusions and outlook}

Although $n$-alkane concentrations are very low in the studied aeolian sediments under desert pavements, it was possible in this pilot study (i) to distinguish between samples from the Black Rock Desert (mainly shrub-derived $n$-alkanes) and from Fuerteventura (mainly grass-derived $n$-alkanes) and (ii) to perform radiocarbon dating on bulk $n$-alkanes. Ongoing studies now aim at building up modern plant and soil reference datasets from the study areas rather than relying on published reference datasets established for central Europe (Schäfer et al., 2016).

The $n$-alkane patterns provide no evidence for major input from soil microorganisms. Further studies investigating the potential role of biological soil crusts for the development of desert pavements focusing on other biomarkers than 
$n$-alkanes are encouraged. The $n$-alkane ${ }^{14} \mathrm{C}$ ages from the Black Rock Desert and from Fuerteventura suggest low organic matter input, low sedimentation rates and low incorporation of root-derived $n$-alkanes. Comparative optically stimulated luminescence dating for the soil profiles under study is in progress.

Data availability. Underlying data can be found in the Supplement.

\section{The Supplement related to this article is available online at https://doi.org/10.5194/egqsj-66-103-2018-supplement.}

Competing interests. The authors declare that they have no conflict of interest.

Acknowledgements. We kindly thank Michael Dietze and Thomas Kolb for support of the field work and all members of the Soil Biogeochemistry Group at the Martin Luther University HalleWittenberg for support of the laboratory work.

\section{References}

Criado, C., Guillou, H., Hansen, A., Hansen, C., Lillo, P., Torres, J. M., and Naranjo, A.: Geomorphological Evolution of Parque Natural de Las Dunas de Corralejo (Fuerteventura, Canary Islands), Reunion Nacional de Geomorfologia, 8, 291-297, 2004.

Dietze, M., Dietze, E., Lomax, J., Fuchs, M., Kleber, A., and Wells, S. G.: Environmental history recorded in aeolian deposits under stone pavements, Mojave Desert, USA, Quaternary Res., 85, 416, 2016.

Faust, D., Yanes, Y., Willkommen, T., Roettig, C., Richter, D., Richter, D., Suchodoletz, H. V., and Zöller, L.: A contribution to the understanding of late Pleistocene dune sand-paleosolsequences in Fuerteventura (Canary Islands), Geomorphology, 246, 290-304, 2015.
Haas, M., Bliedtner, M., Borodynkin, I., Salazar, G., Szidat, S., Eglinton, T. I., and Zech, R.: Radiocarbon Dating of Leaf Waxes in the Loess-Paleosol Sequence Kurtak, Central Siberia, Radiocarbon, 59, 1-12, 2017.

Schäfer, I. K., Lanny, V., Franke, J., Eglinton, T. I., Zech, M., Vysloužilová, B., and Zech, R.: Leaf waxes in litter and topsoils along a European transect, SOIL, 2, 551-564, https://doi.org/10.5194/soil-2-551-2016, 2016.

Schmidt, J.-U.: Bodenevolution während der letzten 30000 Jahre in der Black Rock Desert, W Utah, SW USA, Diploma thesis, Institute of Geography, University of Technology Dresden, Dresden, Germany, 183 pp., 2008.

Szidat, S., Salazar, G. A., Vogel, E., Battaglia, M., Wacker, L., Synal, H. A., and Türler, A.: ${ }^{14} \mathrm{C}$ analysis and sample preparation at the new Bern Laboratory for the Analysis of Radiocarbon with AMS (LARA), Radiocarbon, 56, 561-566, 2014.

Zech, M., Buggle, B., Leiber, K., Markovic, S., Glaser, B., Hambach, U., Huwe, B., Stevens, T., Sümegi, P., Wiesenberg, G., and Zöller, L.: Reconstructing Quaternary vegetation history in the Carpathian Basin, SE Europe, using $n$-alkane biomarkers as molecular fossils, E\&G Quaternary Sci. J., 58, 148-155, 2009.

Zech, M., Zech, R., Buggle, B., and Zöller, L.: Novel methodological approaches in loess research - interrogating biomarkers and compound specific stable isotopes, E\&G Quaternary Sci. J., 60, 170-187, 2011.

Zech, M., Rass, S., Buggle, B., Löscher, M., and Zöller, L.: Reconstruction of the late Quaternary paleoenvironments of the Nussloch loess-paleosol sequence, Germany, using $n$-alkane biomarkers, Quaternary Res., 78, 226-235, 2012.

Zech, M., Krause, T., Meszner, S., and Faust, D.: Incorrect when uncorrected: Reconstructing vegetation history using $n$-alkane biomarkers in loess-paleosol sequences - A case study from the Saxonian loess region, Germany, Quatern. Int., 296, 108-116, 2013.

Zech, M., Kreutzer, S., Zech, R., Goslar, T., Meszner, S., McIntyre, C., Häggi, C., Eglinton, T., Faust, D., and Fuchs, M.: Comparative ${ }^{14} \mathrm{C}$ and OSL dating of loess-paleosol sequences to evaluate post-depositional contamination of $n$-alkane biomarkers, Quaternary Res., 87, 180-189, 2017. 